\title{
Optimizing User's Utility from Cloud Computing Services in a Networked Environment
}

\author{
Eli WEINTRAUB \\ Department of Industrial Engineering and Management \\ Afeka Tel Aviv Academic College of Engineering \\ Tel Aviv, Israel
}

\author{
Yuval COHEN \\ Department of Industrial Engineering and Management \\ Afeka Tel Aviv Academic College of Engineering \\ Tel Aviv, Israel
}

\begin{abstract}
Cloud Computing customers are looking for the best utility for their money. Research shows that functional aspects are considered more important than service prices in customer buying decisions. Choosing the best service provider might be complicated since each provider may sell three kinds of services organized in three layers: SaaS (Software as a service), PaaS (Platform as a service) and IaaS (Infrastructure as a service). This research targets the problem of optimizing consumers' utility, using conjoint analysis methodology. Providers currently offer software services as bundles belonging to the same layer, or to underlying layers. Bundling services prevent customers from splitting their service purchases between a provider of software and a different provider of the underlying layers. This research assumes that in the future will exist a free competitive market, in which consumers will be free to switch their services to different providers, eliminating the negative biases of bundling, during making their buying decisions. This research proposes a mathematical model and three possible strategies for implementation in organizations, and illustrates its advantages compared to existing utility maximization practices. Current conjoint analysis method chooses the best utility in a traditional cloud architecture in which one provider offers a bundle of all three layers. The proposed model assumes a networked cloud architecture in which a customer may choose services from any provider, building for himself the best basket of services maximizing his/her total utility. This research outlines three business models which will assist organizations shift gradually from current $\mathrm{CC}$ architecture to the future networked architectures, thus maximizing their utility.
\end{abstract}

Keywords-Utility Optimization; Cloud Computing; Consumer preferences; Conjoint Analysis

\section{INTRODUCTION}

In the last years organizations began to shift parts of their computing infrastructures outside the geographic organizational borders to the cloud, to other organization which owns the infrastructure. Ref. [15] states that shifting computing facilities outside the organizations' borders enforces establishing new processes of production control, service level monitoring implementing solutions to security and privacy issues. Most definitions of Cloud Computing (CC) state that it's a technology enabling on-demand services, scalability, and flexibility, in computing consumption ([19] [18]). The National Institute of Standards and Technology (NIST) defines $\mathrm{CC}$ as a model which enables convenient, on-demand network access to a shared pool of configurable computing resources that can be rapidly released with minimal service provider interaction [13]. Ref. [12] argues that from time to time cloud providers suffer outages, thus contacting a multi-cloud broker is a preferred solution to keep high up time of services. Service brokers also diminish interfacing efforts needed to various protocols used by service providers. Ref. [1] suggest adding an Inter-Cloud computing layer to $\mathrm{CC}$ systems, which enables to shift resources among cloud systems, thus improving downtime measures and computing resource management. A. Gill, D. Banker, and P. Seltsika [5] who studied the future potential financial services technologies found that $\mathrm{CC}$ is a cost-effective infrastructure compared to traditional infrastructures.

According to [22] CC organizational adoption models can be classified into four types: private, public, community and hybrid. Organizations which adopt the private model, locate its infrastructures outside the organization's sites under the responsibility of a cloud service provider. In a public model, the organization chooses a cloud service provider having the best proposal among cloud public service providers. A public cloud computing provider usually uses the same computing infrastructures for other companies. In a community adoption model, infrastructure services are shared by a group of customers. In a hybrid model, organizations can use infrastructure services supplied by public, private or community providers.

Consumers who wish to use CC services have to decide the selection criteria for evaluating service providers' services. Such a selection might be complicated to measure and compare since providers offer different services having various functionalities, on un-standard scales. Conjoint analysis has been cited in literature as a methodology which enables coping with providers' selection issue. Conjoint analysis has been demonstrated on a common $\mathrm{CC}$ architecture which limits consumers' choices. This research suggests using the conjoint analysis methodology implemented on a networked CC architecture. The research presents a mathematical model and three business strategies which enable maximizing consumers' utility compared to existing business model. The suggested CC architecture is aimed at a future free market competition, in which consumers will be free to choose their service providers improving their utility measures.

The rest of the paper is organized as follows: Section II describes the conjoint analysis methodology, and describes a survey performed, which studied cloud computing consumers' preference attributes. This research defines an optimization model, making use of findings from that previous survey. Section III describes a cloud computing architecture according 
to the current common usage, and according to the new dynamic networked model suggested in literature. Section IV presents and demonstrates the optimization model in the current architecture, and also presents three suggested optimization models implemented on the dynamic architecture. Section $\mathrm{V}$ presents and discusses research findings, and a compares the three suggested optimization models. Finally, section VI suggests future research directions.

\section{CONJOINT ANALYSIS IN ClOUd COMPUTING}

Conjoint analysis is a methodology often used by researchers, aimed at analyzing buyers trade-offs among competing products [6]. The analysis enables simulating and predicting buyers' considerations when they compare different products looking at the characteristics each product resembles. Ref. [2] used the methodology by studying consumers' buying consideration of $\mathrm{CC}$ services, and found that most influencing CC service characteristics are service availability advantages and lock-in prevention. The authors found that consumers did not name cost savings as a major factor influencing their buying decision. P. Koehler, A. Anandasivam, and A. Dan [9] who analyzed consumers' decisions using CC services found that consumers have not mentioned cost savings as a major consideration. According to Ref. [4], information security has been found a barrier to CC adoption. According to Ref. [17], information security is today a barrier to $\mathrm{CC}$ adoption but in the future security will not be a barrier, since information security technologies will become less technological and more effective. Ref. [20] foresees a shift from technology issues to an emphasis on service-based consideration in customer value using CC services.

In the survey performed by P. Koehler, A. Anandasivam, M. Dan, and C. Weinhardt, [8] the researchers asked consumers' about service attribute preferences, and found that the consumers named six attribute levels. The researchers then performed a choice based conjoint analysis and concluded that the attributes were: (1) providers' reputation, (2) required skills, (3) migration process, (4) pricing tariff, (5) cost compared to internal solution and (6) consumer support. Consumers have not mentioned security as a preference attribute. Although security is considered a barrier to adopting CC services as stated above, Ref. [21] states that consumers are un-capable of evaluating the differences in cloud security services. Ref. [8] used conjoint analysis by comparing the relative importance of customers' decision attributes, and found out that provider reputation was the attribute with the highest relative importance of $26 \%$ out of all other attributes, and migration process was the second most important attribute with $21 \%$ importance. The cost has been found only in the fourth place having $16 \%$ relative importance. Table II lists six attribute preference importance levels computed in the research using conjoint analysis methodology. W. Venters and E.A. Whitley [20] who studied the attributes influencing on customers decisions, claim that consumers do not consider CC as an alternative delivery and pricing mechanism, but as a tool that enables creative use of technology for achieving business targets. In Ref. [3] researchers studied the service attributes influencing on $\mathrm{CC}$ adoption. They found seven groups of attributes: Monetary payoff, usability, flexibility, trademark, added value, connectivity and customers' support.
The paper suggests a new model that maximizes consumers' utility in a multi-services providers' environment. The proposed model simulates consumers' choice behavior by finding the maximal utility, assuming that the consumer evaluates his utility by using conjoint analysis technique. This paper develops a model that will enable understanding customers' buying decisions in cloud computing services, assuming that each SP's attributes are given, as previous consumers pointed out during visiting SP's websites. The research also assumes that the consumer can select all combinations of cloud services (SaaS, PaaS, and IaaS) from different providers.

\section{Cloud COMPUTING ARCHITECTUE}

Research literature describes cloud computing architecture as consisting of three layers: IaaS, PaaS and SaaS. Each layer performs certain functions, serving consumers' requests. This separation to layers also fits current services offered by cloud providers. Ref. [22] defines a framework of CC architecture composing three layers of functions supporting cloud computing services. Systems' architectures' components are outlined in Fig. I. White rectangles describe computing services, grey rectangles describe computing resources. Following the functions performed by each layer.

Infrastructure layer - focuses on providing technologies as basic hardware components for software services. There are two kinds of infrastructures: storage capabilities and computing power. Platform layer - includes services which are using cloud infrastructures needed for their functioning. There are two kinds of platform services: development and business platforms. Development platforms are aimed for usage by developers who write programs before transferring them to production and usage by organizations' users. Business platforms enable organizational developers make adaptations of software packages for deployment in their organizations. Application layer - consists of programs and human interfaces used by the organizations' end-users. Applications are running on cloud assets, making use of platform and infrastructure layers. There are two kinds of services in this layer: applications and on-demand services. Application services are software packages ready for end-users such as Microsoft Office, while on-demand services are software applications used by the organizations' customers. Those services are used according to on-demand needs, and used on a pay-per-use or fixed-price pricing model.

To summarize, Service Providers (SP) offer their customers' three kinds of services: IaaS, PaaS and SaaS. Each SP manages all underlying infrastructure for the offered service. For example a SP suggesting a SaaS product usually bundles into the product the PaaS and IaaS layers. Ref. [19] states that according to cloud computing architecture a certain provider may run an application using another provider's infrastructure, but in practice both providers are parts of the same organization. According to current practice, when a provider suggests selling a PaaS service he also bundles the IaaS layer in the deal. Such bundling by service providers limit free market forces from entering the competition, forcing customers pay for components they may buy cheaper from other providers. For example a customer may buy a SaaS 
service from SP1, but buy the underlying PaaS service from SP2 which sells the appropriate platform service cheaper than SP1. Ref. [14] claims that in the future, developers will plan their cloud applications enabling migration of services among clouds of multiple clouds. According to Ref. [24] cloud computing architecture is more modular compared to traditional hosting architectures. CC is based on server farms, with programs running on different layers which are loosely coupled, thus enabling the development of a wide range of applications. Ref. [19] claims it is possible that applications belonging to different layers will run on separate geographical locations even in different countries. Ref. [16] claims that virtual machine migration allows transfer of a running application from one virtual machine to another, which may be provided by a different IaaS provider.

This Research assumes existence of a business model which enables implementing the needed functionalities of a service provider which operates the underlying platform using other service providers, according to consumers' preferences. Implementing this required functionality puts two requirements on cloud architecture. Firstly, the architecture should be based on open standards which will enable interfacing between many components among providers offering all three layers. Second, the architectures' building blocks should be loosely coupled. Implementation of those two functionalities should enable connectivity among vertical and horizontal services, thus elimination of the bundling phenomena defined by E. Weintraub and Y. Cohen [23]. They introduced new definitions of two kinds of bundling: first is horizontal bundling, second is vertical bundling. In horizontal bundling a provider offers several services, all belong to one layer. For example Amazon EC2 offers several bundles each one is composed of the following components: CPU, ECU, memory, instance storage, and operating system. In such bundling situations consumers may not use their own operating system. In vertical bundling a provider offers services which belong to lower layers, in addition to the main needed service. For example Amazon offers SaaS services, in which the consumer is asked to choose the configuration of infrastructure he wants the software application to run. A consumer may not use a PaaS service such as his own operating system. Figure II describes the suggested dynamic cloud architecture. Arrows describe services supplied by underlying layers. Rectangles describe computing services.

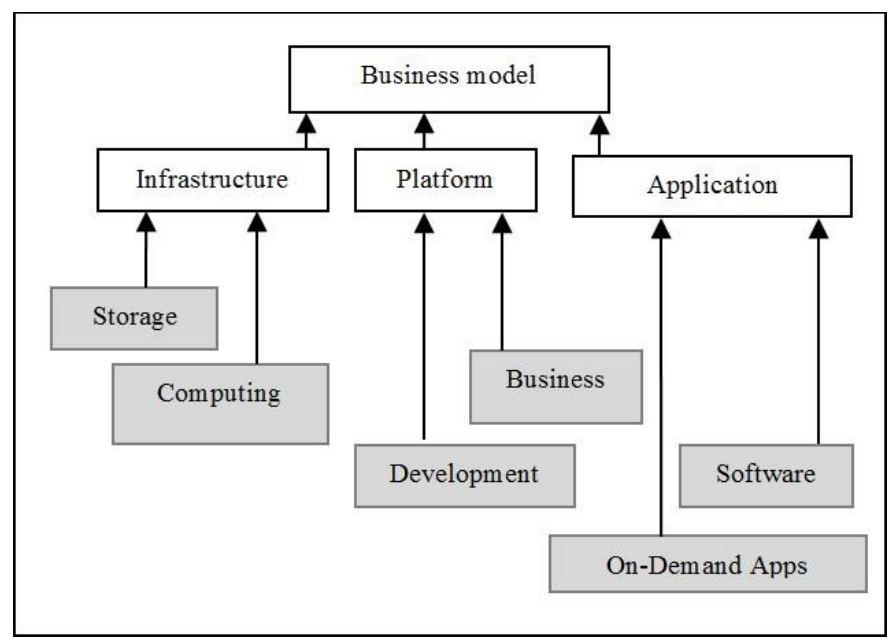

Fig. 1. Current Cloud business model Architecture

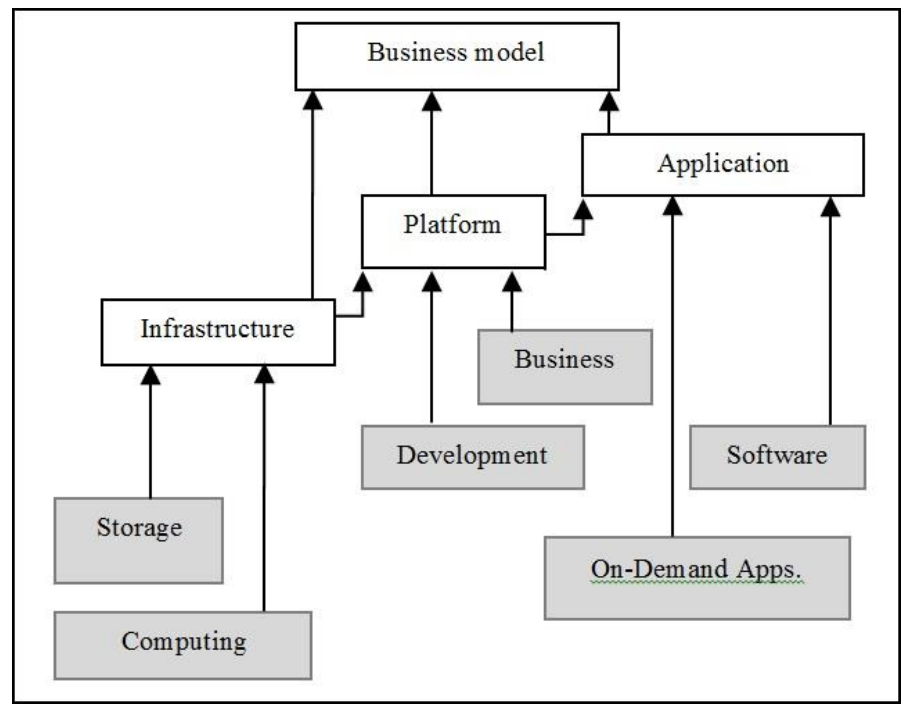

Fig. 2. A Dynamic Architecture for Cloud Computing from Wentraub and Cohen (2015)

\section{CONSUMERs' UTILITY OPTIMIZATION ACCORDING TO CURRENT MODEL}

In an ideal world the optimal service selection is a combination of the maximal utility of each attribute. 
According to current practices most combinations are not feasible or not offered since CC providers offer bundles of services, raising difficulties on consumers wishing to buy certain services from another provider, thus limiting their dependence on the main $\mathrm{CC}$ provider. In order to estimate consumers' preferences, a choice based conjoint analysis, which was first introduced by J.J. Louviere and G.G. Woodworth [11] was included in the survey described in Ref. [9], analyzing service attributes and attribute levels for describing cloud services. Following $\mathrm{R}$. Weiber and $\mathrm{d}$. Mühlhaus [21], A. Hollobaugh [7] generated a list of 18 attributes with 49 attributes' levels. A. Hollobaugh reduced this list by validating it through expert interviews resulting in the final selection of 6 attributes as detailed in Table I [8].

TABLE I. CONSUMERs' SELECTION ATtributes From [8]

\begin{tabular}{|l|l|}
\hline Selection Attribute & Explanation \\
\hline Provider Reputation & $\begin{array}{l}\text { The reputation of the service providers refers to the } \\
\text { attitude, beliefs and trust. }\end{array}$ \\
\hline Required Skills & $\begin{array}{l}\text { Do consumers need to be trained or have specific } \\
\text { skills in order to use the services, can easily use } \\
\text { services. }\end{array}$ \\
\hline Migration Process & $\begin{array}{l}\text { Can users use standard data formats or they have to } \\
\text { use provider specific data formats. }\end{array}$ \\
\hline Pricing Tariff & $\begin{array}{l}\text { Are services offered with a pay-as-you-use tariff, or } \\
\text { with a flat rate tariff in which they can use the } \\
\text { service as often as they want or a one-time-purchase } \\
\text { in which the consumer only pays an initial price at } \\
\text { the first time of use and can use it unlimited. }\end{array}$ \\
\hline $\begin{array}{l}\text { Cost compared to } \\
\text { internal solution }\end{array}$ & $\begin{array}{l}\text { In that survey, Cloud services can have equal costs } \\
\text { compared to an intern solution, but also may have } \\
15 \% \text { less or 25\% less costs. }\end{array}$ \\
\hline Consumer support & $\begin{array}{l}\text { Do providers offer consumer support in different } \\
\text { ways such as FAQ, email, forums etc' if their } \\
\text { consumers need help. }\end{array}$ \\
\hline
\end{tabular}

P. Koehler, A. Anandasivam, M. Dan, and C. Weinhardt [8] created efficient choice sets using SAS, based on W. F. Kuhfeld [10] model. In total, 13 choice sets have been included in the survey, and each consists of three alternatives and one non-choice option. The researchers estimated the part worth utilities for all attributes, except cost reduction, based on Ref. [10] model. The choice decision behavior was predicted using a multinomial Logit choice model (MNL). Afterwards, the part worth utilities were estimated with a maximum likelihood approach (ML) and finally were standardized to relative importance. The null hypothesis that "there are no strictly preferred attributes and all part worth utilities equal zero" was rejected based on a significance level of $\alpha=0.01$ and a likelihood ratio of 161.34. The researchers found that potential consumers of cloud services do have a strong preference with regards to the different service attributes.

TABLE II. CONSUMERs' ATtRibute IMPORTANCE PREFERENCES From [8]

\begin{tabular}{|l|l|}
\hline Selection Attribute & Importance \% \\
\hline Provider reputation & 26 \\
\hline Required skills & 7 \\
\hline Migration process & 21 \\
\hline Pricing tariff & 17 \\
\hline $\begin{array}{l}\text { Cost compared to internal } \\
\text { solution }\end{array}$ & 16 \\
\hline Consumer support & 13 \\
\hline
\end{tabular}

Table II shows the relative importance of all attributes' levels (out of the total sample). Suppose an ideal computing service gives a consumer the maximum utility (100\%). Such a cloud service should be offered by a provider with high reputation ( $26 \%$ relative importance, which is the highest one), operates a smooth migration process $(21 \%)$, and requires no additional training. From an economic point of view, respondents prefer a flat rate pricing model $(17 \%)$ and as much cost reduction as possible (16\%). Corresponding IT support is offered preferably by standard electronic sources (13\%), such as frequently asked questions and documentation. The results provide an idea how consumers' utility reacts to differing some service attributes.

Following, this paper describes a theoretical use case of three SP's and their tariffs, and an organizational customer who wishes to choose certain SP's, based on his business and computing requirements. This paper presents three pricing models which make use of the data described in both previous section and this section.

\section{A. Provider's bundle}

In this section, following a definition of a mathematical model which helps the users in their decision finding the vendor proposing the maximal utility. The model makes use of CC service attributes that contribute value to customers as suggested by [8]. The proposed model is based on the attributes and weights presented in section IV (summarized in tables I and II). The comparison shall use the following use case. A consumer with a list of needed CC services is considering three candidate service providers (named SP1, SP2, SP3) in order to choose a service provider (for this list of services). The consumer must acquire some information related to service qualities of each provider. Some sources of data may be (1) consulting companies, (2) forums, providers (3) white papers and (4) customers' experience related to specific SP. Then, the consumer has to rank the relative grade of the service attributes of each provider. This is, for each service such as "Data transfer" or "Email services" and for each SP, the customers rank the five attributes: (1) Provider reputation, (2) Required skills (3) Migration process (4) Pricing tariff (5) Cost compared to internal solution (6) Consumer support.

The use case defines a scale of numbers from 1 to 3 (where 1 the worst utility level, and 3 is the highest utility level). Of course any scale is acceptable and some would feel more comfortable with a Likert scale of 1 to 5 . For example, Data transfer service for SP1 is graded 132213 yielding an average grade of $59 \%$ detailed in Table III.

Table IV details the grades for this case study for three SP's. The meaning of the upper left grading (132213) is detailed in Table III.

As a demonstration of the model, the use case assumes a user who wants to optimize his utility for the following attribute selection and service levels detailed in Table VI.

The users' general objective is to choose the maximal utility solution for the list of required services. The underlying assumption is that the utilities of all services are computed in the same way by the consumer. 
TABLE III. AN EXAMPLE OF GRADING A SERVICE PROVIDERS' (SP1) SERVICE

\begin{tabular}{|l|l|l|l|}
\hline Selection Attribute & Grade & $\begin{array}{l}\text { Importance } \\
\mathbf{\%}\end{array}$ & Weighted AVG \\
\hline Provider reputation & 1 & 26 & 26 \\
\hline Required skills & 3 & 7 & 21 \\
\hline Migration process & 2 & 21 & 42 \\
\hline Pricing tariff & 2 & 17 & 34 \\
\hline $\begin{array}{l}\text { Cost compared to } \\
\text { internal solution }\end{array}$ & 1 & 16 & 16 \\
\hline Consumer support & 3 & 13 & 39 \\
\hline Total & & & $\mathbf{1 7 8}$ \\
\hline Final grade in \% & & & $\mathbf{1 7 8 / 3 0 0 = 5 9 \%}$ \\
\hline
\end{tabular}

This sub-section is devoted to the first model out of three different maximal utility models to be described in the next sub-sections. The models are based on three architecture configurations according to which the optimal solution is chosen. The first model focuses on choosing a single supplier out of the three in the case study.

TABLE IV. SERVICE UTILITIES OF THREE PROVIDERS. EACH UTILITY IS RanKed by a Grade 1,2 OR 3. SiX SERvice Values of EACH PROVIDER ARE RANKED USING A VECTOR CONTAINING 6 NUMERIC UTILITY GRADES

\begin{tabular}{|l|l|l|l|l|}
\hline SaaS & Service name & $\begin{array}{l}\text { SP1 } \\
\text { Utilities }\end{array}$ & $\begin{array}{l}\text { Sp2 } \\
\text { Utilities }\end{array}$ & $\begin{array}{l}\text { SP3 } \\
\text { Utilities }\end{array}$ \\
\hline & Data transfer & 132213 & 133321 & 232323 \\
\hline & Email services & 332211 & 221213 & 333323 \\
\hline & Cloud search & 332132 & 211132 & 123331 \\
\hline & Documents Mgt. & 131321 & 231231 & 312321 \\
\hline & ERP & 332313 & 111212 & 332131 \\
\hline PaaS & Service name & SP1 Utilities & $\begin{array}{l}\text { Sp2 } \\
\text { Utilities }\end{array}$ & SP3 Utilities \\
\hline & Operating system & 112211 & 323213 & 311121 \\
\hline & Memory & 122132 & 233132 & 121131 \\
\hline & Instance storage & 131121 & 231231 & 312321 \\
\hline & Developer support & 332323 & 311212 & 332131 \\
\hline IaaS & Service name & SP1 Utilities & $\begin{array}{l}\text { Sp2 } \\
\text { Utilities }\end{array}$ & SP3 Utilities \\
\hline & $\begin{array}{l}\text { Relational Database } \\
\text { services }\end{array}$ & 112213 & 133321 & 232323 \\
\hline & $\begin{array}{l}\text { Storage standard } \\
\text { vol. }\end{array}$ & 122211 & 323213 & 311123 \\
\hline & Backup & 112132 & 211132 & 123331 \\
\hline
\end{tabular}

According to the Providers bundle model the consumer has to choose one SaaS provider which adds to his bundle PaaS and IaaS services. This model is characterized by both horizontal and vertical bundling. The consumer has no possibility to choose any service other than the Chosen SP. The calculations start by computing the total utility of each service of each SP. Maximizing consumers' utility in this model is implemented by choosing the SP with the highest utility summing the service utility of all three kinds of services: SaaS, PaaS and IaaS.

Total Utility for the various SPs (see computations below) is: $(\mathrm{SP} 1)=22.04, \mathrm{SP} 2=23.35, \mathrm{SP} 3=25.73$

Thus, SP3 (with highest utility) is chosen. The following is the detailed computation:

Total Utility $(\mathrm{SP} 1)=$

$0.26 \mathrm{x}(1+3+3+1+3+1+1+1+3+1+1+1)+$

$0.07 \times(3+3+3+3+3+1+2+3+3+1+2+1)+$

$0.21 \times(2+2+2+1+2+2+2+1+2+2+2+2)+$

$$
\begin{aligned}
& 0.17 \times(2+2+1+3+3+2+1+1+3+2+2+1)+ \\
& 0.16 \times(1+1+3+2+1+1+3+2+2+1+1+3)+ \\
& 0.13 \times(3+1+2+1+3+1+2+1+3+3+1+2)= \\
= & \mathbf{2 2 . 0 4}
\end{aligned}
$$

Total Utility $($ SP2) $=$

$$
\begin{aligned}
& 0.26 \times(1+2+2+2+1+3+2+2+3+1+3+2)+ \\
& 0.07 \times(3+2+1+3+1+2+3+3+1+3+2+1)+ \\
& 0.21 \times(3+1+1+1+1+3+3+1+1+3+3+1)+ \\
& 0.17 \times(3+2+1+2+2+2+1+2+2+3+2+1)+ \\
& 0.16 \times(2+1+3+3+1+1+3+3+1+2+1+3)+ \\
& 0.13 \times(1+3+2+1+2+3+2+1+2+1+3+2)= \\
= & \mathbf{2 3 . 3 5}
\end{aligned}
$$

Total Utility $($ SP3) $=$

$$
\begin{aligned}
& 0.26 \times(2+3+1+3+3+3+1+3+3+2+3+1)+ \\
& 0.07 \times(3+3+2+1+3+1+2+1+3+3+1+2)+ \\
& 0.21 \times(2+3+3+2+2+1+1+2+2+2+1+3)+ \\
& 0.17 \times(3+3+3+3+1+1+1+3+1+3+1+3)+ \\
& 0.16 \times(2+2+3+2+3+2+3+2+3+2+2+3)+ \\
& 0.13 \times(3+3+1+1+1+1+1+1+1+3+3+1)= \\
= & \mathbf{2 5 . 7 3}
\end{aligned}
$$

To conclude, SP3 is chosen as best utility supplier for the consumer, producing $\mathbf{2 5 . 7 3}$ utility units.

Following, the paper presents a demonstration of choosing the best solution of a CC Hierarchical pricing model.

\section{B. Hierarchical model}

The Hierarchical model assumes the consumer may choose different service providers, but limiting each SP to supply all services requested in each layer. Thus, the vertical bundling constraint is released, but the vertical bundling constraint is still valid. Since fitting SaaS services to the customer is more sensitive to customer requirements (and usually more expensive) - this model assumes that each SP maximizes its SaaS capabilities and looks for purchasing the best combination of platform and infrastructure services that best complements its own offerings in these levels. Since SPs seek simple management and control of sub-contracted services, only one SP could be chosen for complementing the platform or the infrastructure level. The Platform SPs can also purchase infrastructure services. While SaaS is the highest level in the hierarchy, the computations start from the lowest level (IaaS) and progress through PaaS to the decision taken by the SP based on their SaaS and possibly sub-contracted PaaS and/or IaaS. The customer in this model would choose at each level the provider of choice for the requirements.

\section{1) Fist Hierarchical Level}

The calculations start with comparing the infrastructure services of the three candidate SPs, as follows:

IaaS Utility $(\mathrm{SP} 1)=$
$\begin{aligned} & 0.26 \times(1+1+1)+ \\ & 0.07 \times(1+2+1)+ \\ & 0.21 \times(2+2+2)+ \\ & 0.17 \times(2+2+1)+ \\ & 0.16 \times(1+1+3)+ \\ & 0.13 \times(3+1+2)= \\ &= \mathbf{4 . 7 5}\end{aligned}$


IaaS Utility $(\mathrm{SP} 2)=$

$$
\begin{aligned}
& 0.26 \times(1+3+2)+ \\
& 0.07 \times(3+2+1)+ \\
& 0.21 \times(3+3+1)+ \\
& 0.17 \times(3+2+1)+ \\
& 0.16 \times(2+1+3)+ \\
& 0.13 \times(1+3+2)= \\
&= 6.21
\end{aligned}
$$

IaaS Utility $(\mathrm{SP} 3)=$

$$
\begin{array}{ll} 
& 0.26 \times(2+3+1)+ \\
& 0.07 \times(3+1+2)+ \\
0.21 \times(2+1+3)+ \\
0.17 \times(3+1+3)+ \\
0.16 \times(2+2+3)+ \\
0.13 \times(3+3+1)= \\
=\mathbf{6 . 4 6}
\end{array}
$$

Hence SP3 is chosen as best IaaS utility supplier for the consumer, producing $\mathbf{6 . 4 6}$ utility units.

Now PaaS has to be evaluated for the three SPs.

\section{2) Second Hierarchical level}

The calculations start with comparing the platform services of the three candidate SPs, as follows:

PaaS Utility $($ SP1 $)=$

$$
\begin{aligned}
& 0.26 \times(1+1+1+3)+ \\
& 0.07 \times(1+2+3+3)+ \\
& 0.21 \times(2+2+1+2)+ \\
& 0.17 \times(2+1+1+3)+ \\
& 0.16 \times(1+3+2+2)+ \\
& 0.13 \times(1+2+1+3)= \\
& =7.04
\end{aligned}
$$

PaaS Utility $($ SP2 $)=$

$$
\begin{aligned}
& 0.26 \times(3+2+2+3)+ \\
& 0.07 \times(2+3+3+1)+ \\
& 0.21 \times(3+3+1+1)+ \\
& 0.17 \times(2+1+2+2)+ \\
& 0.16 \times(1+3+3+1)+ \\
& 0.13 \times(3+2+1+2)= \\
&=\mathbf{8 . 4 2}
\end{aligned}
$$

PaaS Utility $($ SP3 $)=$

$$
\begin{aligned}
& 0.26 \times(3+1+3+3)+ \\
& 0.07 \times(1+2+1+3)+ \\
& 0.21 \times(1+1+2+2)+ \\
& 0.17 \times(1+1+3+1)+ \\
& 0.16 \times(2+3+2+3)+ \\
& 0.13 \times(1+1+1+1)= \\
&=7.49
\end{aligned}
$$

If platform level SP is chosen independent of other levels SP2 would be chosen as best utility supplier for our consumer, producing $\mathbf{8 . 4 2}$ utility units.

This model assumes now the need of an interfacing fee for connecting a platform held by service provider $i$ to an infrastructure $j$ when the infrastructure belongs to a different service provider. As an example the model assumes that the interfacing fee is worth $\mathbf{0 . 0 5}$ utility units. The model computes now all combinations of a platform service provider and an infrastructure service provider producing maximum utility.

Platform SP1 + Infrastructure SP1 $=7.04+4.75=11.79$

Platform SP2 + Infrastructure SP2 $=8.42+6.21=14.63$

Platform SP3 + Infrastructure SP3 $=7.49+6.46=13.95$

Platform SP1 + Infrastructure SP2 - interface fee $=7.04$ $+6.21-0.05=13.2$

Platform SP1 + Infrastructure SP3 - interface fee $=7.04+$ $6.46-0.05=13.45$

Platform SP2 + Infrastructure SP1 - interface fee $=8.42+$ $4.75-0.05=13.12$

Platform SP2 + Infrastructure SP3 - interface fee = $8.42+6.46-0.05=14.83$

Platform SP3 + Infrastructure SP1 - interface fee $=7.49+$ $4.75-0.05=12.19$

Platform SP3 + Infrastructure SP2 - interface fee $=7.49+$ $6.21-0.05=13.65$

Hence Maximum utility is achieved combining Platform SP2 with IaaS SP3 producing $\mathbf{1 4 . 8 3}$ utility units.

As the interface cost grows, the solutions without interfaces are more attractive.

For example, an interface fee of 0.3 would yield:

Platform SP2 + Infrastructure SP3 - interface fee = $8.42+6.46-0.3=14.58$

whereas Platform SP2 + Infrastructure SP2 $=8.42+$ $6.21=14.63$

So SP2 without any interface becomes the chosen alternative.

Another example assuming no interface fee using the hierarchical model calculating utility:

$$
\begin{aligned}
& \text { Platform SP1 + Infrastructure SP1 }=7.04+4.75=11.79 \\
& \text { Platform SP2 + Infrastructure SP2 }=8.42+6.21=14.63 \\
& \text { Platform SP3 + Infrastructure SP3 }=7.49+6.46=13.95 \\
& \text { Platform SP1 + Infrastructure SP2 }=7.04+6.21=13.25 \\
& \text { Platform SP1 + Infrastructure SP3 }=7.04+6.46=13.50 \\
& \text { Platform SP2 + Infrastructure SP1 }=8.42+4.75=13.17 \\
& \text { Platform SP2 + Infrastructure SP3 = 8.42 }+\mathbf{6 . 4 6}=
\end{aligned}
$$

Platform SP3 + Infrastructure SP1 $=7.49+4.75=12.24$

Platform SP3 + Infrastructure SP2 $=7.49+6.21=13.70$

Hence Maximum utility is achieved combining Platform SP2 with IaaS SP3 producing $\mathbf{1 4 . 8 8}$ utility units.

Now the model considers SaaS and selects the best software service provider.

3) Third Hierarchical Level 
SaaS Utility $(\mathrm{SP} 1)=$

$$
\begin{aligned}
& 0.26 \times(1+3+3+1+3)+ \\
& 0.07 \times(3+3+3+3+3)+ \\
& 0.21 \times(2+2+2+1+2)+ \\
& 0.17 \times(2+2+1+3+3)+ \\
& 0.16 \times(1+1+3+2+1)+ \\
& 0.13 \times(3+1+2+1+3)= \\
&= \mathbf{1 0 . 2 5}
\end{aligned}
$$

SaaS Utility $(\mathrm{SP} 2)=$

$$
\begin{aligned}
& 0.26 \times(1+2+2+2+1)+ \\
& 0.07 \times(3+2+1+3+1)+ \\
& 0.21 \times(3+1+1+1+1)+ \\
& 0.17 \times(3+2+1+2+2)+ \\
& 0.16 \times(2+1+3+3+1)+ \\
& 0.13 \times(1+3+2+1+2)= \\
&= 8.72
\end{aligned}
$$

SaaS Utility $(\mathrm{SP} 3)=$

$$
\begin{aligned}
& 0.26 \times(2+3+1+3+3)+ \\
& 0.07 \times(3+3+2+1+3)+ \\
& 0.21 \times(2+3+3+2+2)+ \\
& 0.17 \times(3+3+3+3+1)+ \\
& 0.10 \times(2+2+3+2+3)+ \\
& 0.11 \times(3+3+1+1+1)= \\
&=11.78
\end{aligned}
$$

From previous stages the model choses the maximal SaaS provider incorporating Platform SP2 and Infrastructure SP3 whose utility is $\mathbf{1 4 . 8 3}$ as computed. 25.03

Software SP1 $+14.83-0.05=10.25+14.83-0.05=$

$$
\begin{aligned}
& \text { Software SP2 }+14.83 \quad=8.72+14.83=23.55 \\
& \text { Software SP3 }+\mathbf{1 4 . 8 3}-\mathbf{0 . 0 5}=\mathbf{1 1 . 7 8}+\mathbf{1 4 . 8 3}-\mathbf{0 . 0 5}= \\
& \mathbf{2 6 . 5 6}
\end{aligned}
$$

Hence the model chooses as maximal utility architecture producing $\mathbf{2 6 . 5 6}$ utility units, offering a combination of service providers: Software SP3, Platform SP2 and Infrastructure SP3.

This selection produces an improved utility $\mathbf{2 6 . 5 6}$ over the providers' bundle model which chose SP3 as maximal utility architecture producing only $\mathbf{2 5 . 7 3}$ utility units. The improved utility is achieved in the hierarchical model in spite of the payoff of two interfacing fees paid for connection software SP3 to platform SP2, and secondly connecting platform SP2 to infrastructure SP3. In this example the model demonstrated using the hierarchical model achieving higher overall utility by using the flexibility of choosing layers of service providers free of hierarchical bundling constraints.

Following, the use case assumes that no interface fee is needed for calculation of the best alternative:

$$
\begin{aligned}
& \text { Software SP1 }+14.88=10.25+14.88=25.13 \\
& \text { Software SP } 2+14.88=8.72+14.88=23.60 \\
& \text { Software SP3 }+\mathbf{1 4 . 8 8}=\mathbf{1 1 . 7 8}+\mathbf{1 4 . 8 8}=\mathbf{2 6 . 6 6}
\end{aligned}
$$

Hence, the model chooses as maximal utility architecture producing $\mathbf{2 6 . 6 6}$ utility units, offering a combination of service providers: Software SP3, Platform SP2 and Infrastructure SP3.

Following, the model presents the third architecture model demonstrating achieving even higher utility by relaxing the horizontal bundling constraints.

\section{Optimized model}

In this model the consumer may choose services freely in a free competitive market, selecting the best service in the market according to the utility gained from the service. In this model both vertical and horizontal bundling are relaxed, and the consumer may choose each service under no constraints whatsoever. The model introduces three sub-models according to fees management strategies.

In this section the paper presents an analysis of the impact of the cost of administrative work (ordering, tracking and payment management) on the optimal policy in a free market setting. First, the paper introduces the simple basic model without fees or costs. Then, the paper presents a maximal utility approach. Finally the paper presents the direct utility comparison for choosing a primary supplier.

\section{1) The Basic Optimized Model}

In this utility model the research assumes free market rules, in which each service is chosen to be the one that brings the highest utility. Table IV summarizes this utility model:

TABLE V. BASIC OPTIMIZED UTILITY MODEL

\begin{tabular}{|l|l|l|l|l|l|l|}
\hline SaaS & Service name & SP1 Utility & Sp2 Utility & SP3 Utility & Max Utility & Best SP \\
\hline & Data transfer & 1.78 & 2.06 & 2.37 & 2.37 & 3 \\
\hline & Email services & 2.04 & 1.76 & 2.84 & 2.84 & 3 \\
\hline & Cloud search & 2.32 & 1.71 & 2.15 & 2.32 & 1 \\
\hline & Documents Mgt. & 1.64 & 1.89 & 2.23 & 2.23 & 3 \\
\hline & ERP & 2.47 & 1.30 & 2.19 & 2.47 & 1 \\
\hline PaaS & Service name & SP1 Utility & Sp2 Utility & & Max Utility & Best SP \\
\hline & Operating system & 1.38 & 2.44 & 1.68 & 2.44 & 2 \\
\hline & Memory & 1.73 & 2.27 & 1.39 & 2.27 & 2 \\
\hline & Instance storage & 1.30 & 1.89 & 2.23 & 2.23 & 3 \\
\hline & Developer support & 2.63 & 1.82 & 2.19 & 2.63 & 1 \\
\hline IaaS & Service name & SP1 Utility & Sp2 Utility & SP3 Utility & Max Utility & Best SP \\
\hline & $\begin{array}{l}\text { Relational Database } \\
\text { Services }\end{array}$ & 1.64 & 2.06 & 2.37 & 2.37 & 3 \\
\hline & Storage standard vol. & 1.45 & 2.44 & 1.94 & 2.44 & 3 \\
\hline & Backup & 1.66 & 1.71 & 2.15 & 2.15 & 3 \\
\hline Total & & & & & $\mathbf{2 8 . 7 6}$ & \\
\hline
\end{tabular}


Ignoring the cost of managing multiple SPs, the total utility in this case would be the sum of the Max utility column: 28.76. This is of course a better utility than the other two utility methods presented above. However, in current market conditions having such a scheme requires continual interface with the various service providers. Such interface requires time and money. Therefore, having the interface and managing the interface with multiple SPs may reduce the attractiveness of this utility optimization scheme.

\section{2) The Maximal Utility Model}

Translating the problem into Minimum cost problem, the research assumes that 28.76 utility score translates to $\$ \mathrm{X}$. The customer must contact at least one SP for making any purchase at all. But for the case study assumes that the customer must contact the other two SPs to establish the purchases and track the transactions. Assuming a monthly cost per SP per service of $\$ 30.00$ for the administrative work of ordering, tracking and payment management yields:

Cost of main SP1 (with 2 service of SP2 and 7 services of SP3): $\mathrm{X}+(7+2) * \$ 30=\$ X+\$ 270$

Cost of main SP2 (with 2 service of SP1 and 7 services of SP3): $X+(7+3) * \$ 30=\$ X+\$ 300$

Cost of main SP3 (with 2 service of SP2 and 3 services of SP1): $\mathrm{X}+(3+2) * \$ 30=\$ X+\$ 150$

Thus, main SP3 is chosen with minimal total monthly expenses of: $\$ \mathbf{X}+\$ \mathbf{1 5 0})$,

If the interface fee is larger than the difference in service price between the alternative provider and the main SP, buying the cheap item from the other SP with the additional cost would be more expensive than buying it from the main SP.

For example, suppose that $\$ 30$ is equivalent to 0.3 units of utility. In that case, checking the services where other SPs have better utility than SP3 yields:
"Cloud search (CS)": U(SP1, CS)-U(SP3, CS) =: 2.32$2.15=0.17<\mathbf{0 . 3} \rightarrow$ choosing $\mathbf{S P 3}$ instead of SP1

ERP: U(SP1,ERP)-USP3,ERP) $=2.47-2.19=0.28<0.3$ $\rightarrow$ choosing SP3 instead of SP1

Operating system (OS): U(SP2,OS)-U(SP3,OS) $=2.44-$ $1.68=0.76>0.3 \rightarrow$ Choosing SP2

Memory $(\mathrm{M}): \quad \mathrm{U}(\mathrm{SP} 2, \mathrm{M})-\mathrm{U}(\mathrm{SP} 3, \mathrm{M})=$ 1.39 $=0.88>\mathbf{0 . 3} \rightarrow$ Choosing SP2

Developer support (DS): U(SP1,DS)-U(SP3,DS) $=2.63-$ 2.19=0.44>0.3 $\rightarrow$ Choosing SP1

Thus, the interface cost is: $3(\$ 30)=\$ 90$ and the overall utility is now: 28.76-0.17-0.28-0.3-0.3-0.3 = 28.76$1.35=27.41$

It is obvious that as the interface cost goes up the optimal solution contains less and less such interfaces thus preferring a sole SP (The provider's full bundle model).

\section{3) The Direct Optimal Utility Comparison Approach}

Let's assume that each interface between two services managed by two SP's reduces utility by 0.05 units. Following a computation of total utility in case SP1 in chosen as main cloud SP. The customer chooses each service according to maximal utility, reducing total utility for all interfacing services.

The model assumes that SP1 is the main service provider, and that the interfacing fee equals 0.05 utility units.

Thus, SP1 as main provider produces 28.31 utility units. Reducing utility by using interfacing fees does not produce a higher utility compared to using a model without fees.

Suppose now SP2 is the main provider, using other SP's services and paying them interfacing fees amounting 0.05 utility units. Following, the research presents the calculations of total utility.

TABLE VI. DIRECT OPTIMIZED UTILITY MODEL FOR MAIN SP1

\begin{tabular}{|c|l|r|r|r|r|c|c|}
\hline SaaS & Service name & $\begin{array}{c}\text { SP1 } \\
\text { Utility }\end{array}$ & $\begin{array}{c}\text { Sp2 } \\
\text { Utility }\end{array}$ & $\begin{array}{c}\text { SP3 } \\
\text { Utility }\end{array}$ & SP2 - Fee & SP3 - Fee & Max (SP1, SP2-fee, SP3-fee) \\
\hline & Data transfer & 1.78 & 2.06 & 2.37 & 2.01 & 2.32 & 2.32 \\
\hline & Email services & 2.04 & 1.76 & 2.84 & 1.71 & 2.79 & 2.79 \\
\hline & Cloud search & 2.32 & 1.71 & 2.15 & 1.66 & 2.10 & 2.32 \\
\hline & Documents Mgt. & 1.64 & 1.89 & 2.23 & 1.84 & 2.18 & 2.18 \\
\hline & ERP & 2.47 & 1.30 & 2.19 & 1.25 & 2.14 & 2.47 \\
\hline PaaS & Service name & SP1 & Sp2 & SP3 & SP2 - Fee & SP3 - Fee & Max (SP1, SP2-fee, SP3-fee) \\
& & 1.38 & 2.44 & 1.68 & 2.39 & 1.63 & 2.39 \\
\hline & Operating system & 1.73 & 2.27 & 1.39 & 2.22 & 1.34 & 2.22 \\
\hline & Memory & 1.30 & 1.89 & 2.23 & 1.84 & 2.18 & 2.18 \\
\hline & Instance storage & 2.63 & 1.82 & 2.19 & 1.77 & 2.14 & 2.63 \\
\hline & Developer support & SP1 & Sp2 & SP3 & SP2-Fee & SP3 - Fee & Max (SP1, SP2-fee, SP3-fee) \\
\hline & Service name & Utility & Utility & Utility & & & 2.32 \\
& $\begin{array}{l}\text { Relational Database } \\
\text { services }\end{array}$ & 1.64 & 2.06 & 2.37 & 2.01 & 2.32 & 2.39 \\
\hline & Storage standard vol. & 1.45 & 2.44 & 1.94 & 2.39 & 1.89 & 2.10 \\
\hline & Backup & 1.66 & 1.71 & 2.15 & 1.66 & 2.10 & \\
\hline Total & & & & & & & \\
\hline
\end{tabular}


TABLE VII. DIRECT OPTIMIZED UTILITY MODEL FOR MAIN SP2

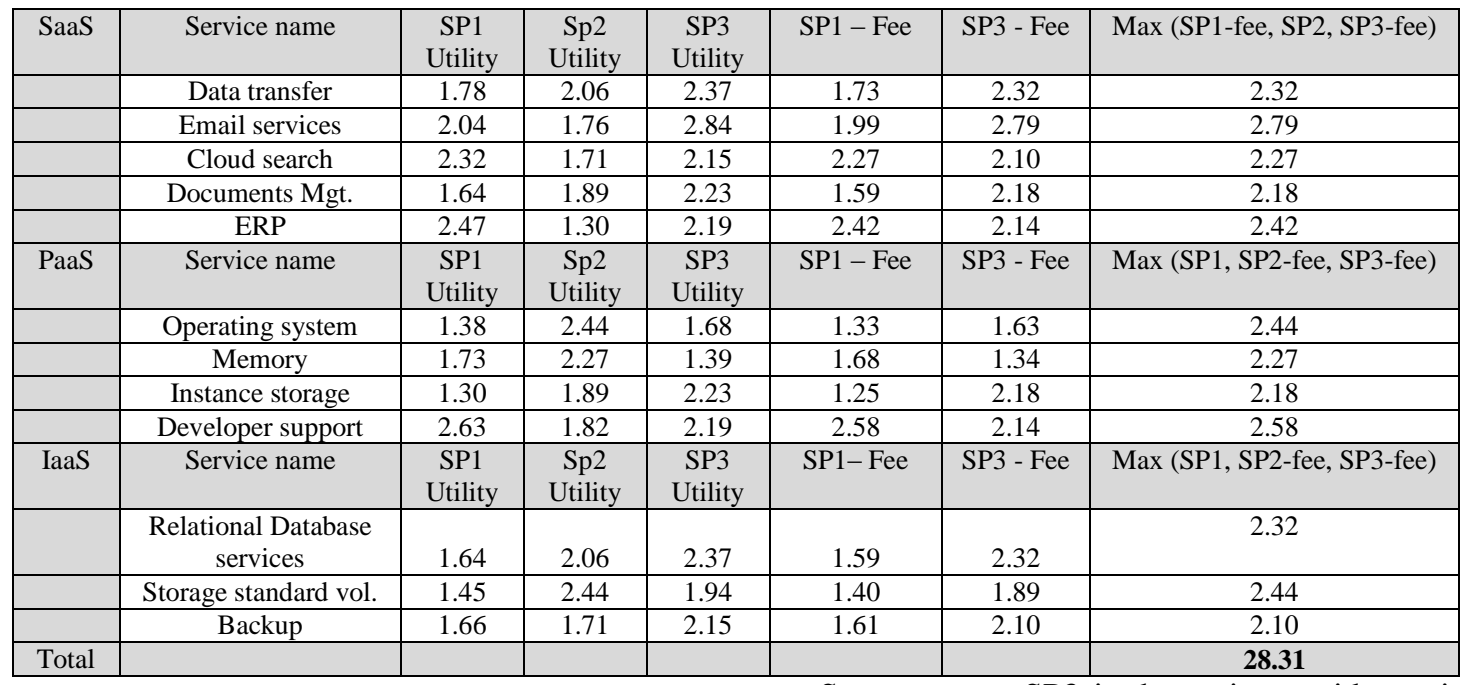

Suppose now SP3 is the main provider, using other SP's

Thus, SP2 as main provider produces 28.31 utility units same as SP1 as main provider. Reducing utility by using interfacing fees does not produce a higher utility compared to 28.76 using the pricing simple model without fees. services and paying them interfacing fees amounting 0.05 utility units. Following, the research presents calculations of total utility.

TABLE VIII. DiRECT OPTIMIZEd UTILITY MODEL FOR MAIN SP3

\begin{tabular}{|c|c|c|c|c|c|c|c|}
\hline SaaS & Service name & $\begin{array}{c}\text { SP1 } \\
\text { Utility }\end{array}$ & $\begin{array}{c}\text { Sp2 } \\
\text { Utility }\end{array}$ & $\begin{array}{c}\text { SP3 } \\
\text { Utility }\end{array}$ & SP1-Fee & SP2 - Fee & Max (SP1-fee, SP2-fee, SP3) \\
\hline & Data transfer & 1.78 & 2.06 & 2.37 & 1.73 & 2.01 & 2.37 \\
\hline & Email services & 2.04 & 1.76 & 2.84 & 1.99 & 1.71 & 2.84 \\
\hline & Cloud search & 2.32 & 1.71 & 2.15 & 2.27 & 1.66 & 2.27 \\
\hline & Documents Mgt. & 1.64 & 1.89 & 2.23 & 1.59 & 1.84 & 2.23 \\
\hline & ERP & 2.47 & 1.30 & 2.19 & 2.42 & 1.25 & 2.42 \\
\hline PaaS & Service name & $\begin{array}{c}\text { SP1 } \\
\text { Utility }\end{array}$ & $\begin{array}{c}\text { Sp2 } \\
\text { Utility }\end{array}$ & $\begin{array}{c}\text { SP3 } \\
\text { Utility }\end{array}$ & SP1-Fee & SP2-Fee & Max (SP1-fee, SP2-fee, SP3) \\
\hline & Operating system & 1.38 & 2.44 & 1.68 & 1.33 & 2.39 & 2.39 \\
\hline & Memory & 1.73 & 2.27 & 1.39 & 1.68 & 2.22 & 2.22 \\
\hline & Instance storage & 1.30 & 1.89 & 2.23 & 1.25 & 1.84 & 2.23 \\
\hline & Developer support & 2.63 & 1.82 & 2.19 & 2.58 & 1.77 & 2.58 \\
\hline IaaS & Service name & $\begin{array}{c}\text { SP1 } \\
\text { Utility }\end{array}$ & $\begin{array}{c}\text { Sp2 } \\
\text { Utility }\end{array}$ & $\begin{array}{c}\text { SP3 } \\
\text { Utility } \\
\end{array}$ & SP1-Fee & SP2 - Fee & Max (SP1-fee, SP2-fee, SP3) \\
\hline & $\begin{array}{c}\text { Relational Database } \\
\text { services }\end{array}$ & 1.64 & 2.06 & 2.37 & 1.59 & 2.01 & 2.37 \\
\hline & Storage standard vol. & 1.45 & 2.44 & 1.94 & 1.40 & 2.39 & 2.39 \\
\hline & Backup & 1.66 & 1.71 & 2.15 & 1.61 & 1.66 & 2.15 \\
\hline Total & & & & & & & 28.46 \\
\hline
\end{tabular}

Thus, SP3 as main provider produces $\mathbf{2 8 . 4 6}$ utility units, improving utility over SP1 and SP2 (which is 28.31).

Note that, the optimized pricing model using interfacing fees worth 0.05 utility units does not produce a higher utility

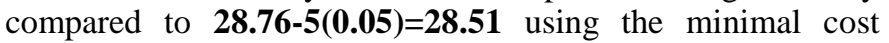
approach of section 3.2 .
Following, the research presents in Fig. III a sensitivity analysis assuming that SP3 is the main provider, computing the impact of varying interfacing fees on the calculations of best utility, according to all three models. 


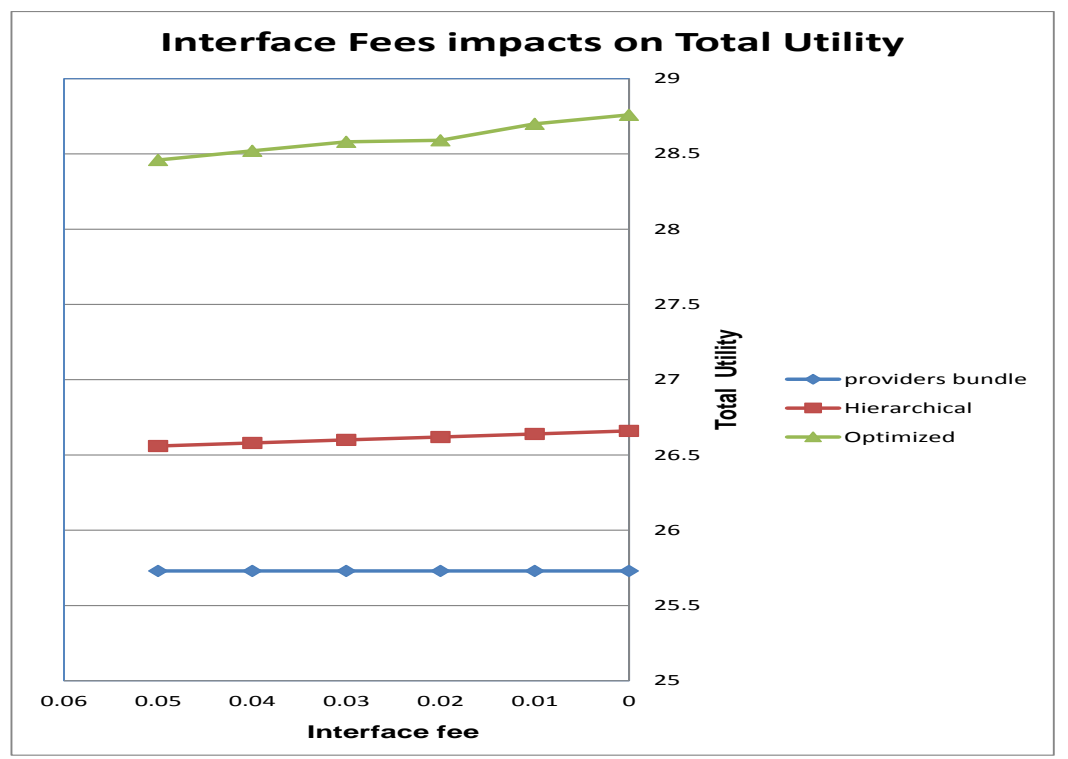

Fig. 3. Sensitivity Analysis assuming sp3 main Service Provider

First, the research assumes the interfacing fee reduces utility by 0.01 units. The research compares the calculated utility to the best utility produced by SP3. Table VIII presents computed utilities assuming an interfacing fee cost of 0.01 utility units (total utility: 28.7). Changing the assumption to interfacing fee cost of 0.02 units maximal utility provides 28.59 utility units.

Assuming the interfacing fee reduces utility by 0.03 units maximal utility provides 28.58 utility units.

Assuming the interfacing fee reduces utility by 0.04 units maximal utility provides 28.52 utility units.

Thus, a situation where all providers use standard interfaces in a free competition, consumers gain maximum utility. As interface costs of non-standard providers grow, the total utility for the consumer declines.
Notice that the providers-bundle model produces minimal utility, which is naturally unaffected by interface fees, since there are no interfaces.

The hierarchical model produces an improved utility over the bundle. Maximal utility is gained when no interface fees are used. Usage of interfaces diminishes utility since the consumer has to pay extra fees interfacing variety of providers.

Best utility is achieved using the optimized model. Interfacing fees impact on diminishing utility. Such expenses are needed as long as providers are using non-standard protocols, forcing consumers to pay for communicating between different standards. In a future situation when free market competition will force providers use standard protocols, consumers will be able to gain the maximal utility.

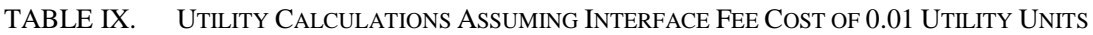

\begin{tabular}{|c|c|c|c|c|c|c|c|}
\hline SaaS & Service name & $\begin{array}{c}\text { SP1 } \\
\text { Utility }\end{array}$ & $\begin{array}{c}\text { Sp2 } \\
\text { Utility }\end{array}$ & $\begin{array}{l}\text { SP3 } \\
\text { Utility }\end{array}$ & SP1 - Fee & SP2 - Fee & Max (SP1-fee, SP2-fee, SP3) \\
\hline & Data transfer & 1.78 & 2.06 & 2.37 & 1.77 & 2.05 & 2.37 \\
\hline & Email services & 2.04 & 1.76 & 2.84 & 2.03 & 1.75 & 2.84 \\
\hline & Cloud search & 2.32 & 1.71 & 2.15 & 2.31 & 1.70 & 2.31 \\
\hline & Documents Mgt. & 1.64 & 1.89 & 2.23 & 1.63 & 1.88 & 2.23 \\
\hline & ERP & 2.47 & 1.30 & 2.19 & 2.46 & 1.29 & 2.46 \\
\hline PaaS & Service name & $\begin{array}{c}\text { SP1 } \\
\text { Utility }\end{array}$ & $\begin{array}{c}\text { Sp2 } \\
\text { Utility }\end{array}$ & $\begin{array}{c}\text { SP3 } \\
\text { Utility }\end{array}$ & SP1-Fee & SP2 - Fee & Max (SP1-fee, SP2-fee, SP3) \\
\hline & Operating system & 1.38 & 2.44 & 1.68 & 1.37 & 2.43 & 2.43 \\
\hline & Memory & 1.73 & 2.27 & 1.39 & 1.72 & 2.26 & 2.26 \\
\hline & Instance storage & 1.30 & 1.89 & 2.23 & 1.29 & 1.88 & 2.23 \\
\hline & Developer support & 2.63 & 1.82 & 2.19 & 2.62 & 1.81 & 2.62 \\
\hline IaaS & Service name & $\begin{array}{c}\text { SP1 } \\
\text { Utility }\end{array}$ & $\begin{array}{c}\mathrm{Sp} 2 \\
\text { Utility }\end{array}$ & $\begin{array}{l}\text { SP3 } \\
\text { Utility }\end{array}$ & SP1-Fee & SP2-Fee & Max (SP1-fee, SP2-fee, SP3) \\
\hline & $\begin{array}{l}\text { Relational Database } \\
\text { services }\end{array}$ & 1.64 & 2.06 & 2.37 & 1.63 & 2.05 & 2.37 \\
\hline & Storage standard vol. & 1.45 & 2.44 & 1.94 & 1.44 & 2.43 & 2.43 \\
\hline & Backup & 1.66 & 1.71 & 2.15 & 1.65 & 1.70 & 2.15 \\
\hline Total & & & & & & & 28.70 \\
\hline
\end{tabular}




\section{CONCLUSIONS}

This paper presents a model that is based on conjoint analysis method to measure the utility of $\mathrm{CC}$ service utilities under the major stages in the scale between full bundling of CC services, through partial bundling, to free market conditions. The customer is trying to maximize his/her overall utility while facing open tariffs of various services from the various SPs.

Current SPs practices of bundling services blocks and obstructs market competition in cloud computing. In the long run (with the addition of SPs) economic competition theory predicts that full bundling will disappear with the rise of free market forces. As CC service competition will develop, and tools to enable this will be more common consumers are bound to look for an optimized combination of services and service providers that maximize their utility under the prevalent market conditions. The research presented three major stages of shifting to a free market, and showed the optimal customers' strategy in each stage. At first, the research ignores SP interface/monitoring costs, and shows that as the level of freedom to switch services grows, so is the overall utility. However, the cost of interfacing multiple SPs is a tradeoff, very large interface cost have the same effect as bundling, and are making the single SPs more attractive. Finally, the research presents a detailed case study implementation of the model and its stages and strategies illustrate the advantages of the proposed strategies compared to existing practices used by cloud computing consumers.

Three directions are identified for future research, based on this paper:

1) Examining the effects of uncertainty on consumer's choice.

2) Considering risk and risk aversion on consumer's choice.

3) Developing a model which describes the behavior of both the consumers and the CC service providers based on game theory.

\section{REFERENCES}

[1] T. Aoyama, and H. Sakai, "Inter-Cloud Computing", Business Information Systems Engineering, Vol. 3, 2013.

[2] M. A. Armbrust, R.Fox, A.J. Griffith, R. Katz, A. Konwinski, G. Lee, D. Patterson, A. Rabkin, I. Stoica, and M. Zaharia., Above the Clouds: A "Berkeley View of Cloud Computing". Technical Report, Berkeley:CA,.2009.

[3] K. Bogataj, and A. Pucihar, "Business Model Factors Influencing Cloud Computing Adoption: Differences in Opinion”, BLED 2013 Conference Proceedings, Bled:Slovenia, 2013.

[4] Z. Chen, F. Han, J. Cao, X. Jiang, and S. Chen, "Cloud ComputingBased Forensic Analysis for Collaborative Network Security Management System". Tsinghua science and technology, Vol 18, No. (1, 2), 2013.

[5] A. Gill, D. Banker, and P. Seltsika, "Moving Forward: Emerging Themes in Financial Services Technologies Adoption", Communications of the Association for Information Systems: Vol. 36, Article 12, 2015.
[6] P. E. Green, A. M. Krieger, and Y. J. Wind, "Thirty Years of Conjoint Analysis: Reflections and Prospects”. Interfaces Vol. 31, No.3, 2001, pp. 56-73.

[7] A. Hollobaugh, "Hosting.com Cloud Computing Trends Repor"t, Technical Report, 2009. http://www.hosting.com.

[8] P. Koehler, A. Anandasivam, M. Dan, and C. Weinhardt, "Customer heterogeneity and tariff biases in cloud computing". Thirty First International Conference on Information Systems, St. Louis 20101 (ICIS 2010) proceedings, 2010.

[9] P. Koehler, A. Anandasivam, and A. Dan, "Cloud services from a consumer perspective", AMCIS 2010 Proceedings, 2010.

[10] W. F. Kuhfeld, "Marketing Research Methods in SAS Experimental Design, Choice", Conjoint and Graphical Techniques. Technical Report, 2009.

[11] J. J. Louviere and G. G. Woodworth, "Design and Analysis of Simulated Consumer Choice or Allocation Experiments: an Approach based on Aggregate Data". Journal of Marketing Research, Vol. 20, 1983, pp. 350-367.

[12] Y. Mansouri, A. N. Toosi, and R. Buyya, "Brokering Algorithms for Optimizing the Availability and Cost of Cloud Storage Services", 2013 IEEE International Conference on Cloud Computing Technology and Science, 2013.

[13] P. Mell, and T. Grance, "The NIST definition of cloud computing", National Institute of Standards and Technology, NIST, Vol. 53 No. 6, 2009, p. 50.

[14] F. Paraiso, N. Haderer, P. Merle, R. Rouvoy, and L.Seinturier, "A Federated Multi-Cloud PaaS Infrastructure", 2012 IEEE Fifth International Conference on Cloud Computing, 2012.

[15] T. Pueschel, A. Anandasivam, S. Buschek, and D. Neumann, "Making money with clouds: Revenue optimization through automated policy decisions". $17^{\text {th }}$ ECIS - European Conference on Information Systems, 2009.

[16] U. Z. Rehman, F. K. Hussain, and O. K. Hussain, "Towards MultiCriteria Cloud Service Selection”, 2011 Fifth International Conference on Innovative Mobile and Internet Services in Ubiquitous Computing, 2011.

[17] J. S. Forrester, "Cloud predictions for 2014: Cloud joins the IT portfolio", http://blogs.forrester.com/james_staten/13-12-04cloud_computing_predictions_for_2014_cloud_joins_the_formal_it_por tfolio, accessed 02 March 2014.

[18] L. Vaquero, L. Rodero-Merino, J. Caceres, and M. Lindner, “A Break in the Clouds: Towards a Cloud Definition", Editorial note. ACM SIGCOMM (2009). Computer Communication Review 50, Volume 39, Number 1, 2009.

[19] A. Velte, R. Elsenpeter, and T. J.Velte, "Cloud Computing: A practical approach". Tata McGraw-Hill Education Pvt. Ltd, 2009.

[20] W .Venters, and E.A.Whitley, "A critical review of cloud computing: researching desires and realities", Journal of Information Technology, Vol. 27, No.3, 2012, pp. 179-197.

[21] R. Weiber, and D. Mühlhaus, "Auswahl von Eigenschaften und Ausprägungen bei der Conjointanalyse". In "Conjointanalyse", by D. Baier and M. Brusch, Heidelberg: Springer, 2009, pp.43-58..

[22] C. Weinhardt, B.Blau, and J. Stößer, "Cloud Computing - A Classification, Business Models, and Research Directions". Business \& Information Systems Engineering, 2009.

[23] E. Weintraub, and Y. Cohen, "Cost Optimization of Cloud Computing Services in a Networked Environment", (IJACSA) International Journal of Advanced Computer Science and Applications ,Vol. 6, No. 4, 2015, pp. 148-157.

[24] Q. Zhang, L. Cheng, and R. Bautaba, "Cloud computing: State-of-theart and Research challenges". Journal of Internetional Service Applications, Vol. 1, 2010, pp. 7-18. 